\title{
Enhancing the Optical Properties of Chitosan, Carboxymethyl Cellulose, Sodium Alginate Modified with Nano Metal Oxide and Graphene Oxide
}

\section{Amina Omar}

Ain Shams University Faculty of Science

\section{Rania Badry}

Ain Shams University Girls' College for Arts Science and Education: Ain Shams University Faculty of

Women for Arts Science and Education

\section{Maroof A. Hegazy}

NRIAG: National Research Institute of Astronomy and Geophysics

\section{Ibrahim S. Yahia}

King khaled University

\section{Hanan Elhaes}

Ain Shams University Womens College for Arts Science and Education: Ain Shams University Faculty of Women for Arts Science and Education

\section{Heba Y. Zahran}

King Khaled University

Medhat IBRAHIM ( $\sim$ medahmed6@yahoo.com )

NRC, Egypt

\section{Ahmed Refaat}

SESSAME

\section{Research Article}

Keywords: Chitosan, CMC, Sodium alginate, TiO2, Graphene oxide, Optical properties

Posted Date: January 12th, 2022

DOI: https://doi.org/10.21203/rs.3.rs-1079643/v1

License: (c) (1) This work is licensed under a Creative Commons Attribution 4.0 International License.

Read Full License 


\section{Abstract}

The solution casting method was utilized to synthesize nanocomposite films of chitosan (Cs)/CuO, $\mathrm{Cs} /$ graphene oxide (GO), carboxymethyl cellulose (CMC)/ $/ \mathrm{TiO}_{2}, \mathrm{CMC} / \mathrm{GO}$, sodium alginate ( $\left.\mathrm{Na} \mathrm{Alg}\right) / \mathrm{TiO}_{2}$, and $\mathrm{Na}-\mathrm{Alg} / \mathrm{GO}$ owing to their various applications. The influence of $\mathrm{CuO}, \mathrm{TiO}_{2}$ and $\mathrm{GO}$ concentration on the optical properties of $\mathrm{Cs}, \mathrm{CMC}$ and Na-Alg films was studied by UV-Vis Spectroscopy. The absorbance of $\mathrm{Cs}, \mathrm{CMC}$ and $\mathrm{Na}$-Alg increased with increasing the filler content, thus reflecting the dependence of $\mathrm{Cs}$, $\mathrm{CMC}$, and Na-Alg properties on the nanofiller content, and confirming the interactions between individual polymers and $\mathrm{CuO}, \mathrm{TiO}_{2}$ and $\mathrm{GO}$ nanoparticles. The obtained absorbance values were then used to calculate the absorption coefficient and, hence, the optical band gap values. The characteristic absorption bands of $\mathrm{CuO}$ and $\mathrm{TiO}_{2}$ underwent a redshift by increasing the filler content. The results showed that the optical band gap of Cs, CMC, and Na-Alg decreased with filler content, and they possessed 1, 2 and 2 band gaps respectively. The obtained results recommended that Cs, CMC, and NaAlg nanocomposites can be used in optoelectronic devices.

\section{Introduction}

The need to fabricate new safe materials is growing due to steady increase in environmental pollution. Therefore, the development of new environmentally friendly materials has become popular (Guido K. et al. 2003; Xu T. 2005; Vilela C et al. 2018). Using natural composite materials, not only means utilizing environmentally friendly and safe materials, but also allowing the best use of the characteristics of the raw materials by compensating for defects in individual parts and increasing its practical value. The negative influences of utilizing plastic bags, for example, can be diminished by utilizing composite materials in food packaging (Kunz D. A. 2013; Qiu J. et al. and Tang Y. et al. 2016).

Careful selection of the raw materials makes it possible to produce composite films with specific characteristics such as biodegradability and antibacterial properties, which is effective for almost all applications (Tharanathan R. N. 2003; Li F. et al. 2015). Over the past few decades, there has been a growing interest in the invention and development of metal ion-polysaccharide complexes to be used in many popular applications such as metal collection, water purification, formation of new catalysts, and many other industrial applications (Khalil K. D. et al. 2020).

Chitosan (Cs), a cationic polysaccharide composed of $(1,4)$ linked 2-aminodeoxy- $\beta D$-glucans, is the deacetylated form of chitin. Cs is characterized by its antibacterial activity, non-toxicity, biocompatibility, biodegradability, antioxidant activity, and film-forming ability. The protonable amino group present along the D-glucosamine residues of Cs plays a key role in explaining most of its favorable properties especially in the field of biomaterials such as mucoadhesion, haemostatic activity, permeation-enhancing property, and analgesic effect (Croisier F. and Jérôme C. 2013). Cs films are selectively permeable to sense toxic gases such as $\mathrm{CO}_{2}$ and $\mathrm{CO}$ (Othan S.H. 2019; Xu D. et al. 2021). Hussein E. M. et al. 2021 prepared nanocomposite films based on $\mathrm{Cs}$ and titanium dioxide $\left(\mathrm{TiO}_{2}\right)$ nanoparticles utilizing the solution casting method. 
Cellulose and its derivatives such as cellulose acetate and carboxymethyl cellulose have a wide range of applications including food packaging, thickener, plasticizer, pharmaceuticals, cosmetics, and optoelectronic devices. Carboxymethyl cellulose (CMC) is a plant-derived cellulose derivative, a polyanionic polymer and a water-soluble polysaccharide (Yu J. et al. 2021). CMC possesses low conductivity and must be salt doped to increase its conductivity for use in energy storage devices. ElNaggar M.E. et al. 2021 fabricated a nanocomposite membrane material based on silicon oxide nanoparticles and poly(3,4-ethylene dioxythiophene) incorporated into cellulose acetate matrix. Ezzat D. et al. 2021 studied the dielectric properties of cellulose acetate-molybdenum trioxide nanocomposites. Badry R. et al 2020 studied the electronic properties of CMC blended with polyethylene oxide and acetic acid theoretically.

Sodium alginate (Na-Alg) is a natural polysaccharide extracted from brown algae. From a molecular point of view, Na-Alg is a linear, water-soluble, biodegradable, and biocompatible polysaccharide composed of (1-4) linked $\beta$-d mannonate $(M)$ and a -I guluronate $(G)$ units. The presence of carboxyl A group in the NaAlg structure provides electronegative properties to other polymers in aqueous solution (Essifi K. et al. and Zhao X. 2021). As Na-Alg is biocompatible, biodegradable, and non-toxic, with its ability to undergo facile synthesis of fine particles, as well as its gelling properties when cross-linked with divalent ions such as calcium and iron cations, it is widely applied in food and pharmaceutical industries (Zhao X. et al and Yang Y. 2021; Berraaouan D. et al 2017).

Transition metal oxides are the most interesting semiconductors because they can be applied to storage devices, electronics, and catalysis (Rashad M. 2020; El-Shamy A. G. et al. 2017). Incorporation of metal oxide nanoparticles into polar polymers alters many properties of the polymer. In addition, they can also be utilized for electronics, optics, and catalysis (Jamróz E. 2019; Taghizadeh S. M. 2020; Badry R. 2021-c)

$\mathrm{Cs}, \mathrm{CMC}$, and Na-Alg were selected for this study because of their favorable properties and capability of forming membranes. In this study, copper oxide ( $\mathrm{CuO}), \mathrm{TiO}_{2}$ and graphene oxide (GO) were infused into the natural polymer matrix as dopants for enhancing the optical properties of $\mathrm{Cs}, \mathrm{CMC}$, and Na-Alg. Ultraviolet-visible (UV-Vis) spectroscopy has been utilized to report the influence of dopants on the optical properties of the polymers. Therefore, the major purpose of this work is to develop active films based on a mixture of natural polymer, and metal oxides and graphene oxide nanoparticles.

\section{Materials And Methods}

\subsection{Materials}

Cs with a medium molecular weight was purchased from Sigma Aldrich. CMC with $2.5 \times 10^{5} \mathrm{~g} / \mathrm{mol}$ molecular weight was purchased from K. Patel Chemo-pharma PVT, India. Na-Alg was purshased from Qualikems company, India. Sodium hydroxide $(\mathrm{NaOH})(\geq 97 \%)$, potassium permanganate $\left(\mathrm{KMnO}_{4}\right)$ (99\%), phosphoric acid (85\%), and graphite powder were purchased from Fisher Chemical. Hydrogen 
peroxide $\left(\mathrm{H}_{2} \mathrm{O}_{2}\right)(30 \%)$ was purchased from Piochem and sulfuric acid $(96 \%)$ was acquired from Scharlau.

\subsection{ZnO Nanoparticles preparation}

$\mathrm{ZnO}$ nanoparticles (ZnO-NP) were produced using the coprecipitation method. A solution of $1 \mathrm{M}$ zinc acetate dihydrate in $100 \mathrm{ml}$ deionized water was prepared at $70^{\circ} \mathrm{C} .2 \mathrm{M} \mathrm{NaOH}$ was dissolved in $100 \mathrm{ml}$ of deionized water. $\mathrm{NaOH}$ was then added dropwise to the zinc acetate solution with strong stirring for $1 \mathrm{hr}$. The white precipitate was separated by centrifugation at $1000 \mathrm{rpm}$ and washing with deionized water three times. The resulting precipitate was dried overnight in a dryer at $80^{\circ} \mathrm{C}$ and calcinated at $500^{\circ} \mathrm{C}$ for 2 hrs.

\subsection{GO preparation}

$\mathrm{GO}$ nanoparticles were synthesized using Hummer's method. $\mathrm{H}_{2} \mathrm{SO}_{4}$ and $\mathrm{H}_{3} \mathrm{PO}_{4}$ were mixed in a beaker in a 9:1 ratio. In another beaker, a mixture of $6 \mathrm{~g} \mathrm{KMnO}_{4}$ and $1 \mathrm{~g}$ graphite powder was prepared in an ice bath. The two solutions were then mixed and stirred at $50^{\circ} \mathrm{C}$ for $12 \mathrm{hrs}$. After cooling the mixture, it was poured into $1 \mathrm{ml}$ of ice containing $30 \% \mathrm{H}_{2} \mathrm{O}_{2}$. The precipitate was collected by centrifugation at 10,000 $\mathrm{rpm}$, first washed with $200 \mathrm{ml}$ of $30 \% \mathrm{HCl}$, then washed several times with deionized water, and finally dried overnight in a room temperature vacuum oven.

\subsection{Chitosan/ZnO nanocomposite preparation}

$0.5 \mathrm{~g}$ of Cs was dissolved in $50 \mathrm{ml}$ of deionized water under vigorous stirring at $60^{\circ} \mathrm{C}$ for $1 \mathrm{hr}$ until Cs was completely dissolved and a viscous solution was obtained. $\mathrm{CuO}$ nanoparticles were added to $\mathrm{Cs}$ solution with different weight percentages $(2,4,6$ and $8 \mathrm{wt} \%)$ as tabulated in Table 1 . The $\mathrm{Cs} / \mathrm{CuO}$ solution was stirred for $2 \mathrm{hrs}$ until $\mathrm{CuO}$ nanoparticles were dispersed completely. The solution was cast in plastic petri dishes and left to dry in air for 5 days at $40^{\circ} \mathrm{C}$.

Table 1

Composition of $\mathrm{Cs} / \mathrm{CuO}$ nanocomposite

films

\begin{tabular}{|llll|}
\hline Sample & Cs $(\mathbf{g})$ & CuO (g) & GO (g) \\
\hline C1 & 0.50 & 0.00 & 0.00 \\
\hline C2 & 0.49 & 0.01 & 0.00 \\
\hline C3 & 0.48 & 0.02 & 0.00 \\
\hline C4 & 0.47 & 0.03 & 0.00 \\
\hline C5 & 0.46 & 0.04 & 0.00 \\
\hline C6 & 0.49 & 0.00 & 0.01 \\
\hline
\end{tabular}

\section{5. $\mathrm{CMC} / \mathrm{TiO}_{2}$ nanocomposite preparation}


$0.5 \mathrm{~g}$ of $\mathrm{CMC}$ was dissolved in $50 \mathrm{ml}$ of deionized water under vigorous stirring at $50^{\circ} \mathrm{C}$ for $1 \mathrm{hr}$ until CMC was completely dissolved and a viscous solution was obtained. $\mathrm{TiO}_{2}$ nanoparticles were added to $\mathrm{CMC}$ solution with different weight percentages $(2,4,6$ and $8 \mathrm{wt} \%)$ as presented in Table 2 . The $\mathrm{CMC} / \mathrm{TiO}_{2}$ solution was stirred for $1 \mathrm{hr}$, then the solution was sonicated for $1 \mathrm{hr}$ for more dispersion of $\mathrm{TiO}_{2}$ nanoparticles. The solution was cast in plastic petri dishes and left to dry in air for 5 days.

Table 2

Composition of $\mathrm{CMC} / \mathrm{TiO}_{2}$ nanocomposites

\begin{tabular}{|llll|}
\hline Sample & $\mathbf{C M C}(\mathbf{g})$ & $\mathrm{TiO}_{2}(\mathbf{g})$ & $\mathbf{G O}(\mathbf{g})$ \\
\hline $\mathrm{C} 1$ & 0.50 & 0.00 & 0.00 \\
\hline $\mathrm{C} 2$ & 0.49 & 0.01 & 0.00 \\
\hline $\mathrm{C} 3$ & 0.48 & 0.02 & 0.00 \\
\hline $\mathrm{C} 4$ & 0.47 & 0.03 & 0.00 \\
\hline $\mathrm{C} 5$ & 0.46 & 0.04 & 0.00 \\
\hline $\mathrm{C} 6$ & 0.49 & 0.00 & 0.01 \\
\hline
\end{tabular}

\section{6. $\mathrm{Na}-\mathrm{Alg} / \mathrm{TiO}_{2}$ nanocomposite preparation}

$\mathrm{Na}$-Alg solution was prepared by dissolving $0.5 \mathrm{~g}$ of $\mathrm{Na}-\mathrm{Alg}$ in $50 \mathrm{ml}$ of deionized water and stirred vigorously for $1 \mathrm{hr}$ at $50^{\circ} \mathrm{C}$. After a clear viscous solution of $\mathrm{Na}$-Alg is obtained, $\mathrm{TiO}_{2}$ nanoparticles was added with different concentrations $(2,4,6$ and $8 \mathrm{wt} \%)$. Table 3 shows the different compositions of Na$\mathrm{Alg} / \mathrm{TiO}_{2}$ films. The last solutions of $\mathrm{Na}-\mathrm{Alg} / \mathrm{TiO}_{2}$ were stirred additionally for $1 \mathrm{hr}$. To achieve a complete dispersion of $\mathrm{TiO}_{2}$ nanoparticles, the solutions were sonicated for additionally $30 \mathrm{~min}$ at $60^{\circ} \mathrm{C}$. The resulting solutions were then cast in plastic petri dishes and left to dry in air for 5 days.

Table 3

Composition of $\mathrm{Na}-\mathrm{Alg} / \mathrm{TiO}_{2}$ nanocomposites

\begin{tabular}{|llll|}
\hline Sample & Na-Alg (g) & TiO2 (g) & GO (g) \\
\hline N1 & 0.50 & 0.00 & 0.00 \\
\hline N2 & 0.49 & 0.01 & 0.00 \\
\hline N3 & 0.48 & 0.02 & 0.00 \\
\hline N4 & 0.47 & 0.03 & 0.00 \\
\hline N5 & 0.46 & 0.04 & 0.00 \\
\hline N6 & 0.49 & 0.00 & 0.01 \\
\hline
\end{tabular}




\section{Characterizing Techniques \\ 3.1. UV-vis. measurement}

UV-Vis spectra for all polymer nanocomposites were collected at room temperature in the wavelength range of 200-1000 nm, using a Jasco V-630 (Japan) spectrophotometer at Spectroscopy Department, National Research Centre, Cairo, Egypt.

\section{Results And Discussion}

\subsection{UV-vis. absorption results}

Determination of the optical characteristics of polymers and metal oxides is of a great interest to investigate their different applications. Fig. 1 shows the absorbance spectra of pure $\mathrm{Cs}, \mathrm{Cs} / \mathrm{CuO}$ films and $\mathrm{Cs} / \mathrm{GO}$ film versus wavelength collected in the optical range from 200 to $1000 \mathrm{~nm}$. In certain cases, the absorption spectrum measurements of $\mathrm{CuO}$ nanoparticles produce an optimum absorption band at 242 $\mathrm{nm}$ and another band in the range of $400-600 \mathrm{~nm}$ (Rashad, M. et al. 2013) as illustrated in Fig. 1. There is another band at nearly $670 \mathrm{~nm}$ and its intensity increased with increasing CuO content. As presented in the figure, the characteristic absorption band of Cs appeared at nearly $214 \mathrm{~nm}$ which is attributed to the $n-\pi^{*}$ and $\pi-\pi^{*}$ transition of $C=C$ and $C=0$, and refers to the presence of acetate group residuals. The absorption shoulder beyond $300 \mathrm{~nm}$ is attributed to the $\mathrm{CuO}$ nanoparticles.

The absorption spectra of $\mathrm{CMC}, \mathrm{CMC} / \mathrm{TiO}_{2}$ nanocomposite films that contains different amounts of $\mathrm{TiO}_{2}$ $(2,4,6$ and $8 \mathrm{wt} \%)$, and $\mathrm{CMC} / \mathrm{GO}$ film, recorded in the range of $200-800 \mathrm{~nm}$, are displayed in Fig. 2. As displayed in the figure, the absorbance of pristine $\mathrm{CMC}$ was strongly influenced by the addition of $\mathrm{TiO}_{2}$ and GO separately. As the CMC absorption edge undergoes a shift towards the higher wavelength region, the figure shows that the intensity of absorption increases with increasing $\mathrm{TiO}_{2}$ content in the samples which refers to the strong complexation between $\mathrm{CMC}$, and $\mathrm{TiO}_{2}$ and $\mathrm{GO}$ separately. The characteristic absorption band of $\mathrm{TiO}_{2}$ nanoparticles undergoes a slight blue shift with decreasing the $\mathrm{CMC}$ content in the prepared nanocomposites. The characteristic absorption band observed at $207 \mathrm{~nm}$ was ascribed to $\mathrm{n}$ $\pi^{*}$ transitions and that at $345 \mathrm{~nm}$ was attributed to $\pi-\pi^{*}$ which is characteristic for the $\mathrm{TiO}_{2}$ nanoparticles, and similarly for CMC/GO film (Ali H. E. et al. 2015; Alsulami Q. A. and Rajeh A. 2021). This means that the $\mathrm{CMC} / \mathrm{TiO}_{2}$ nanocomposites have lower particle size.

Figure 3 shows the UV-Vis absorption spectra of pure $\mathrm{Na}-\mathrm{Alg}$, and $\mathrm{Na}-\mathrm{Alg} / \mathrm{TiO}_{2}$ and $\mathrm{Na}-\mathrm{Alg} / \mathrm{GO}$ nanocomposites. The characteristic absorption peak of $\mathrm{TiO}_{2}$ nanoparticles is clearly obvious in the Na$\mathrm{Alg} / \mathrm{TiO}_{2}$ nanocomposites absorption spectra. The redshift of the absorption peaks from 346 to $360 \mathrm{~nm}$ can be attributed to the particle size variation during the reaction. Size and morphology of the prepared nanoparticles control the electronic properties of the nanocomposites (Farea M. O. et al. 2020; FloresHernández C. G. et al. 2021). At low concentrations of $\mathrm{TiO}_{2}$, very broad absorption peak is observed with 
very low intensity which shows that the number of particles is small with larger particle size. As the concentration increases, the absorption peak becomes narrower with increment in the intensity together with a redshift in the wavelength, indicating that larger particles are formed.

\subsection{Optical bandgap results}

The optical absorption of polymer nanocomposites is the most important parameter through which the understanding of the band structure of all solids becomes possible. The Beer-Lambert law can be utilized to determine the absorption coefficient ( $a$ ) of the prepared nanocomposites. The absorption coefficient can be determined directly using the following equation:

$a=\left(2.303^{\star} A\right) / d(1)$

Where, $A$ is the absorbance and $d$ is the sample thickness. It is known that the optical bandgap of the different materials can be determined from the electron transition between valance and conduction bands (the fundamental absorption). As reported by Tauc and Davis - Mott, the bandgap values, and the type of electron transition between the valence and conduction bands can be determined using the following equation:

$(a h u)^{r}=B\left(h u-E_{g}\right)(2)$

Where hu is the energy of the incident photons, $\mathrm{B}$ is a constant and $\mathrm{r}$ is a constant that depends on the type of transition. The constant $r$ takes values of $2,1 / 2,2 / 3$ and $1 / 3$ for direct allowed, direct forbidden, indirect allowed or indirect forbidden transition respectively (Badry R. et al. 2021-a and b).

Based on previous work (Kocyigit A. et al. 2020) the type of electronic transition in Cs is direct allowed transition. The direct bandgap energy of pristine $\mathrm{Cs}, \mathrm{Cs} / \mathrm{CuO}$ nanocomposites and $\mathrm{Cs} / \mathrm{GO}$ nanocomposites is plotted as a function of photon energy in Fig. 4- $a, b$, and c respectively. Based on the intercept of the linear part of the curves with the photon energy axis, the values of the direct bandgaps were calculated from the last three figures and recorded in Table 4.

From the figure, the direct bandgap energy value of pure Cs is determined and is equal to $2.66 \mathrm{eV}$, while those of Cs/CuO nanocomposites, as tabulated in Table 4, are 1.66, 1.73, 1.62 and $1.47 \mathrm{eV}$ for 2, 4, 6 and $8 \mathrm{wt} \%$ respectively. On the other hand, for $\mathrm{Cs} / \mathrm{GO}$ nanocomposites, two absorption shoulders were observed corresponding to two bandgaps. The direct allowed bandgaps of $\mathrm{Cs} / \mathrm{GO}$ film were estimated as 1.22 and $5.68 \mathrm{eV}$. The reduction of the Cs bandgap can be attributed to the formation of chemical bonds between $\mathrm{Cs}$ and $\mathrm{CuO}$ nanoparticles that causes the localized states to generate energy between the bands of the highest occupied molecular orbital and the lowest unoccupied one, thus making the lower transitions feasible (Harun M.H. et al. 2009). Therefore, decreasing the direct allowed optical bandgap of pure $\mathrm{Cs}$ was achieved with the incorporation of $\mathrm{CuO}$ and $\mathrm{GO}$. This result reflects that with increasing $\mathrm{CuO}$ content, the direct allowed energy bandgaps decrease in the Cs matrix by increasing the conjugation between $\mathrm{Cs}$ unsaturated bonds and $\mathrm{CuO}$ nanoparticles, aiming to reduce the energy bandgap. Previous 
work confirmed that organic polymers and their nanocomposites with reasonable optical bandgaps are imperative for photonics, and optoelectronic applications. It can then be concluded that $\mathrm{Cs} / \mathrm{CuO}$ and Cs/GO nanocomposites can be used in optoelectronic devices.

Table 4

\begin{tabular}{|c|c|c|}
\hline Sample & $\mathrm{Eg}_{1}(\mathrm{eV})$ & $\mathrm{Eg}_{2}(\mathrm{eV})$ \\
\hline C1 & 2.66 & - \\
\hline $\mathrm{C} 2$ & 1.66 & - \\
\hline C3 & 1.73 & - \\
\hline C4 & 1.62 & - \\
\hline C5 & 1.47 & - \\
\hline C6 & 1.22 & 5.68 \\
\hline
\end{tabular}

Regarding the $\mathrm{CMC} / \mathrm{TiO}_{2}$ nanocomposite films, it was found that $\mathrm{CMC}$ has more than one direct bandgap due to its amorphousity, as presented in Figure 5, which are equal to 3.93 and $5.04 \mathrm{eV}$. Table 5 presents the different values of the optical bandgap for pristine $\mathrm{CMC}, \mathrm{CMC} / \mathrm{TiO}_{2}$ and $\mathrm{CMC} / \mathrm{GO}$. Figure 5 demonstrates that the addition of different weight percentages of $\mathrm{TiO}_{2}(2,4,6$ and $8 \mathrm{wt} \%)$ to $\mathrm{CMC}$ reduces the optical bandgap of $\mathrm{CMC}$. Based on the obtained results, it was found that all the prepared samples have two direct bandgaps and one indirect bandgap due to the formation of localized states within the valence band of $\mathrm{CMC}$ (Elkomy G. M. et al. 2016). For $\mathrm{CMC} / \mathrm{TiO}_{2}$ samples, the first bandgap initially decreased until reaching $2.11 \mathrm{eV}$ and then increased again. The reason for this decrease in the bandgap may be attributed to the decrease in the particle size due to the quantum effects. However, increasing the direct optical bandgap beyond $6 \mathrm{wt} \%$ of $\mathrm{TiO}_{2}$ refers to the formation of ion clusters which decreases the mobility, hence increasing the bandgap. These values are determined as presented in Figures 5 and 6 . Therefore, it can be concluded that the sample containing $6 \mathrm{wt} \% \mathrm{TiO}_{2}$ is the preferred one as it has the lowest bandgap energy. On the other hand, for $\mathrm{CMC} / \mathrm{GO}$ nanocomposite film, the first bandgap of CMC decreased to $2.04 \mathrm{eV}$. This decrease in the CMC optical bandgap is attributed to the presence of a new energy levels within the optical bandgap, which facilitates the electrons movement from the valence band to these localized states within the conduction band, consequently increasing conductivity and decreasing the optical bandgap (Murri R., et al. 1992). However, the second bandgap corresponding to the second absorption edge in the low wavelength region changes irregularly due to the addition of $\mathrm{TiO}_{2}$ and $\mathrm{GO}$ to $\mathrm{CMC}$. 
Table 5

Direct $\left(\mathrm{Ed}_{\mathrm{g} 1}\right.$ and $\left.\mathrm{Ed}_{\mathrm{g} 2}\right)$ and indirect $\left(\mathrm{Ei}_{\mathrm{g}}\right)$ optical bandgap of pure $\mathrm{CMC}, \mathrm{CMC}$ substituted with 2 , 4,6 and $8 \mathrm{wt} \% \mathrm{TiO}_{2}$ and $2 \mathrm{wt} \% \mathrm{GO}$

\begin{tabular}{|llll|}
\hline Sample & $\mathrm{Ed}_{\mathrm{g} 1}(\mathrm{eV})$ & $\mathrm{Ed}_{\mathrm{g} 2}(\mathrm{eV})$ & $\mathrm{Ei}_{\mathrm{g}}(\mathrm{eV})$ \\
\hline $\mathrm{C} 1$ & 3.93 & 5.04 & 4.66 \\
$\mathrm{C} 2$ & 2.50 & 5.11 & 4.24 \\
$\mathrm{C} 3$ & 2.30 & 5.34 & 4.33 \\
\hline $\mathrm{C} 4$ & 2.11 & 4.91 & 3.05 \\
\hline $\mathrm{C} 5$ & 2.55 & 4.76 & 1.86 \\
\hline $\mathrm{C} 6$ & 2.04 & 3.31 & - \\
\hline
\end{tabular}

Figure 7 shows the plot of (ahu $)^{2}$ versus the photon energy (hu) for pure $\mathrm{Na}-\mathrm{Alg}, \mathrm{Na}-\mathrm{Alg} / \mathrm{TiO}_{2}$ and $\mathrm{Na}$ Alg/GO film. It is established that, for direct optical bandgap materials, the valence band top and the conduction band bottom have the same zero k-vector. All of the prepared samples possess two optical bandgaps; the onset bandgap equals $3.90 \mathrm{eV}$ and the HOMO/LUMO gap equal $5.57 \mathrm{eV}$ for pure Na-Alg. It is critical to show that the optical bandgap decreased from $3.90 \mathrm{eV}$ for pure Na-Alg to $2.21 \mathrm{eV}$ for Na-Alg doped with $6 \mathrm{wt} \%$ of $\mathrm{TiO}_{2}$ nanoparticles. Additionally, the HOMO/LUMO bandgap of pure Na-Alg (second bandgap) was decreased to $3.57 \mathrm{eV}$ corresponding to $6 \mathrm{wt} \%$ of $\mathrm{TiO}_{2}$. However, the optical bandgap for all samples is still smaller than that for pure Na-Alg. Additionally, Na-Alg/GO nanocomposites have two optical bandgaps. However, the onset bandgap decreased strongly with the addition of GO when compared with that of both pure $\mathrm{Na}-\mathrm{Alg}$ and $\mathrm{Na}-\mathrm{Alg} / \mathrm{TiO}_{2}$ samples. The small optical bandgap of the $\mathrm{Na}$ $\mathrm{Alg} / \mathrm{TiO}_{2}$ and $\mathrm{Na}-\mathrm{Alg} / \mathrm{GO}$ nanocomposites confirms its suitability for optoelectronics, photonics, and solar cell applications (Murri R., et al. 1992; Elkomy G. M. et al. 2016) 
Table 6

Optical direct bandgap for pure Na-Alg and Na-Alg substituted with 2, 4, 6 and $8 \mathrm{wt} \% \mathrm{TiO}_{2}$, and 2 wt\% GO nanocomposite films

\begin{tabular}{|lll|}
\hline Sample & $E_{\mathbf{g} 1}(e V)$ & $E_{g 2}(e V)$ \\
\hline N1 & 3.90 & 5.57 \\
\hline N2 & 2.31 & 5.42 \\
\hline N3 & 2.44 & 5.08 \\
\hline N4 & 2.21 & 3.57 \\
\hline N5 & 2.21 & 3.61 \\
\hline N6 & 2.10 & 5.52 \\
\hline
\end{tabular}

\section{Conclusion}

The traditional casting method was utilized to prepare $\mathrm{Cs} / \mathrm{CuO}, \mathrm{Cs} / \mathrm{GO}, \mathrm{CMC} / \mathrm{TiO}_{2}, \mathrm{CMC} / \mathrm{GO}, \mathrm{Na}-\mathrm{Alg} / \mathrm{TiO}_{2}$ and $\mathrm{Na}$-Alg/GO nanocomposite films by incorporating $\mathrm{CuO}, \mathrm{TiO}_{2}$ and $\mathrm{GO}$ nanoparticles within the polymer matrix. The optical properties of the synthesized nanocomposite films were investigated. The absorbance of $\mathrm{Cs} / \mathrm{CuO}, \mathrm{Cs} / \mathrm{GO}, \mathrm{CMC} / \mathrm{TiO}_{2}, \mathrm{CMC} / \mathrm{GO}, \mathrm{Na}-\mathrm{Alg} / \mathrm{TiO}_{2}$ and $\mathrm{Na}-\mathrm{Alg} / \mathrm{GO}$ films were increased and the UV protection for $\mathrm{Cs}, \mathrm{CMC}$ and $\mathrm{Na}$-Alg was improved upon the addition of nanoparticles. Furthermore, the prepared nanocomposites of $\mathrm{Cs} / \mathrm{CuO}, \mathrm{Cs} / \mathrm{GO}, \mathrm{CMC} / \mathrm{TiO}_{2}, \mathrm{CMC} / \mathrm{GO}, \mathrm{Na}-\mathrm{Alg} / \mathrm{TiO}_{2}$ and $\mathrm{Na}-\mathrm{Alg} / \mathrm{GO}$ can be utilized in many optical applications since the energy bandgap value is reduced due to the incorporation of different nanoparticles, with increase in the wavelength of the electronic transmission. The obtained results of the current study indicated that $\mathrm{Cs}, \mathrm{CMC}$, and $\mathrm{Na}$-Alg nanocomposite films can be utilized as a new membrane material in optoelectronic devices, solar cells, and capacitors.

\section{Declarations}

\section{Acknowledgements}

The authors extend their appreciation to the Scientific Research Deanship at King Khalid University and the Ministry of Education in KSA for funding this research work through the project number IFP-KKU2020/10.

\section{References}

1. Ali, H. E., Atta, A., Senna, M. M.: Physico-chemical properties of carboxymethyl cellulose $(\mathrm{CMC})$ /nanosized titanium oxide (TiO2) gamma irradiated composite. Arab J. Nucl. Sci. Appl. 48(4), 44-52 (2015) 
2. Alsulami, Q. A., Rajeh, A.: Synthesis of the SWCNTs/TiO2 nanostructure and its effect study on the thermal, optical, and conductivity properties of the CMC/PEO blend. Results Phys. 28, 104675 (2021).

3. Badry, R., Elhaes, H., Nada, N., Ibrahim, M.: Study of the Electronic Properties of Solid Polymer Electrolytes Based on Blends of CMC, PEO, and Acetic Acid. Biointerface Res. Appl. Chem. 11, 1100911002 (2021)

4. Badry, R., El-Khodary, S., Elhaes, H., Nada, N., Ibrahim, M.: Optical, conductivity and dielectric properties of plasticized solid polymer electrolytes based on blends of sodium carboxymethyl cellulose and polyethylene oxide. Opt. Quantum Electron. 53(1), 1-15 (2021)

5. Badry, R., Ezzat, H. A., El-Khodary, S., Morsy, M., Elhaes, H., Nada, N., Ibrahim, M.: Spectroscopic and thermal analyses for the effect of acetic acid on the plasticized sodium carboxymethyl cellulose. J. Mole Struct. 1224, 129013 (2021)

6. Badry, R., Fahmy, A., Ibrahim, A., Elhaes, H., Ibrahim, M.: Application of polyvinyl alcohol/polypropylene/zinc oxide nanocomposites as sensor: modeling approach. Opt. Quantum Electron. 53(1), 1-12 (2021)

7. Berraaouan, D., Elmiz, M., Salhi, S., Tahani, A.: Effect of calcium chloride on rheological behavior of sodium alginate. Adv. Mater. Proc. 2, 629-633 (2017)

8. Croisier, F., Jérôme, C.: Chitosan-based biomaterials for tissue engineering. Eur. Polym. J. 49(4), 780$792(2013)$

9. Elkomy, G. M., Mousa, S. M., Mostafa, H. A.: Structural and optical properties of pure PVA/PPY and cobalt chloride doped PVA/PPY films. Arab. J. Chem. 9, S1786-S1792 (2016)

10. Elkomy, G. M., Mousa, S. M., Mostafa, H. A.: Structural and optical properties of pure PVA/PPY and cobalt chloride doped PVA/PPY films. Arab. J. Chem. 9, S1786-S1792 (2016)

11. El-Naggar, M. E., Abdel-Karim, A., Radwan, E. K., Sharmoukh, W., Wassel, A. R., Bayoumy, A. M., Ibrahim, M.: Experimental and theoretical investigations on fouling resistant cellulose acetate/SiO2 NPs/PEDOT ultrafiltration nanocomposite membranes. J. Clean. Prod. 129288 (2021)

12. El-Shamy, A. G., Attia, W. M., Abd El Kader, K. M.: Enhancement of the conductivity and dielectric properties of PVA/Ag nanocomposite films using y irradiation. Mater. Chem. Phys. 191, 225-229 (2017)

13. Essifi, K., Brahmi, M., Berraaouan, D., Ed-Daoui, A., El Bachiri, A., Fauconnier, M. L., Tahani, A. Influence of Sodium Alginate Concentration on Microcapsules Properties Foreseeing the Protection and Controlled Release of Bioactive Substances. J. Chem. 2021(2021)

14. Ezzat, D., Youssif, M., Elhaes, H., El-Nahass, M.: ICMMS-2: Dielectric Relaxation Behaviour and AC Electrical Conductivity of Cellulose Acetate-Molybdenum Trioxide Nanoparticle Blended Film. Egypt. J. Chem. 64(3), 5-7 (2021)

15. Farea, M. O., Abdelghany, A. M., Oraby, A. H.: Optical and dielectric characteristics of polyethylene oxide/sodium alginate-modified gold nanocomposites. RSC Adv. 10(62), 37621-37630 (2020) 
16. Flores-Hernández, C. G., Cornejo-Villegas, M. D. L. A., Moreno-Martell, A., Del Real, A.: Synthesis of a Biodegradable Polymer of Poly (Sodium Alginate/Ethyl Acrylate). Polymers, 13(4), 504 (2021)

17. Harun, M. H., Saion, E., Kassim, A., Mahmud, E., Hussain, M. Y., Mustafa, I. S.: Dielectric properties of poly (vinyl alcohol)/polypyrrole composite polymer films. J. Adv. Sci. Arts, 1(1), 9-16 (2009)

18. Hussein, E. M., Desoky, W. M., Hanafy, M. F., Guirguis, O. W.: Effect of TiO2 nanoparticles on the structural configurations and thermal, mechanical, and optical properties of chitosan/TiO2 nanoparticle composites. J. Phys. Chem. 152, 109983 (2021)

19. Jamróz, E., Kulawik, P., Kopel, P.: The effect of nanofillers on the functional properties of biopolymerbased films: A review. Polymers, 11(4), 675 (2019)

20. Khalil, K. D., Bashal, A. H., Khalafalla, M., Zaki, A. A.: Synthesis, structural, dielectric and optical properties of chitosan-MgO nanocomposite. J. Taibah Univ. Sci. 14(1), 975-983 (2020)

21. Kickelbick, G.: Concepts for the incorporation of inorganic building blocks into organic polymers on a nanoscale. Prog. Polym. Sci. 28(1), 83-114 (2003)

22. Kocyigit, A., Yilmaz, M., Aydogan, S., Incekara, U., Sahin, Y.: The performance of chitosan layer in $\mathrm{Au} / \mathrm{n}$-Si sandwich structures as a barrier modifier. Polym Test. 89, 106546 (2020)

23. Kunz, D. A., Schmid, J., Feicht, P., Erath, J., Fery, A., Breu, J.: Clay-based nanocomposite coating for flexible optoelectronics applying commercial polymers. ACS nano 7(5), 4275-4280 (2013)

24. Li, F., Mascheroni, E., Piergiovanni, L.: The potential of nanocellulose in the packaging field: a review. Packag. Technol. Sci. 28(6), 475-508 (2015)

25. Murri, R., Schiavulli, L., Pinto, N., Ligonzo, T.: Urbach tail in amorphous gallium arsenide films. J. Non. Cryst. Solids 139, 60-66 (1992)

26. Othman, S. H., Kechik, N. R., Shapi'i, R. A., Talib, R. A., Tawakkal, I. S. Water sorption and mechanical properties of starch/chitosan nanoparticle films. J. Nanomater. 2019 (2019)

27. Qiu, J., Wang, L., Uchiya, K., Sakai, E. Effects of injection molding conditions on the electrical properties of polycarbonate/carbon nanotube nanocomposites. Polym. Compos. 37(11), 3245-3255 (2016)

28. Rashad, M., Rüsing, M., Berth, G., Lischka, K., Pawlis, A.: CuO and Co304 nanoparticles: synthesis, characterizations, and Raman spectroscopy. J. Nanomater., 2013 (2013)

29. Rashad, M.: Tuning optical properties of polyvinyl alcohol doped with different metal oxide nanoparticles. Opt. Mater. 105, 109857 (2020)

30. Shetty, S. K., Ismayil, Shetty, G.: Enhancement of Electrical and Optical Properties of Sodium Bromide Doped Carboxymethyl Cellulose Biopolymer Electrolyte Films. J. Macromol. Sci. Phys. B 59(4), 235247 (2020)

31. Taghizadeh, S. M., Lal, N., Ebrahiminezhad, A., Moeini, F., Seifan, M., Ghasemi, Y., Berenjian, A.: Green and economic fabrication of zinc oxide ( $\mathrm{ZnO}$ ) nanorods as a broadband UV blocker and antimicrobial agent. J. Nanomater. 10(3), 530 (2020) 
32. Tang, Y., Hu, X., Zhang, X., Guo, D., Zhang, J., Kong, F.: Chitosan/titanium dioxide nanocomposite coatings: Rheological behavior and surface application to cellulosic paper. Carbohydr. Polym. 151, 752-759 (2016)

33. Tharanathan, R. N.: Biodegradable films and composite coatings: past, present and future. Trends Food Sci Technol 14(3), 71-78 (2003)

34. Vilela, C., Pinto, R. J. B., Pinto, S., Marques, P., Silvestre, A., Barros, C. S. D. R. F.: PolysaccharidesBased Hybrids with Metal Nanoparticles. Springer Cham. 9-30 (2018)

35. Xu, D., Chen, T., Liu, Y.: The physical properties, antioxidant and antimicrobial activity of chitosangelatin edible films incorporated with the extract from hop plant. Polym. Bull. 78(7), 3607-3624 (2021)

36. Xu, T.: Ion exchange membranes: state of their development and perspective. J. Membr. Sci. 263(1-2), 1-29 (2005)

37. Yang, Y., Chen, X., Li, Y., Yin, Z., Bao, M.: Construction of a superhydrophobic sodium alginate aerogel for efficient oil absorption and emulsion separation. Langmuir 37(2), 882-893 (2021)

38. Yu, J., Wang, L., Zhao, Y., Zhou, C.: Preparation, characterization, and antibacterial property of carboxymethyl cellulose derivatives bearing tetrabutylammonium salt. Int. J. Biol. Macromol. 176, 72-77 (2021)

39. Zhao, X., Wang, X., Lou, T.: Preparation of fibrous chitosan/sodium alginate composite foams for the adsorption of cationic and anionic dyes. J. Hazard. Mater. 403, 124054 (2021)

\section{Figures}




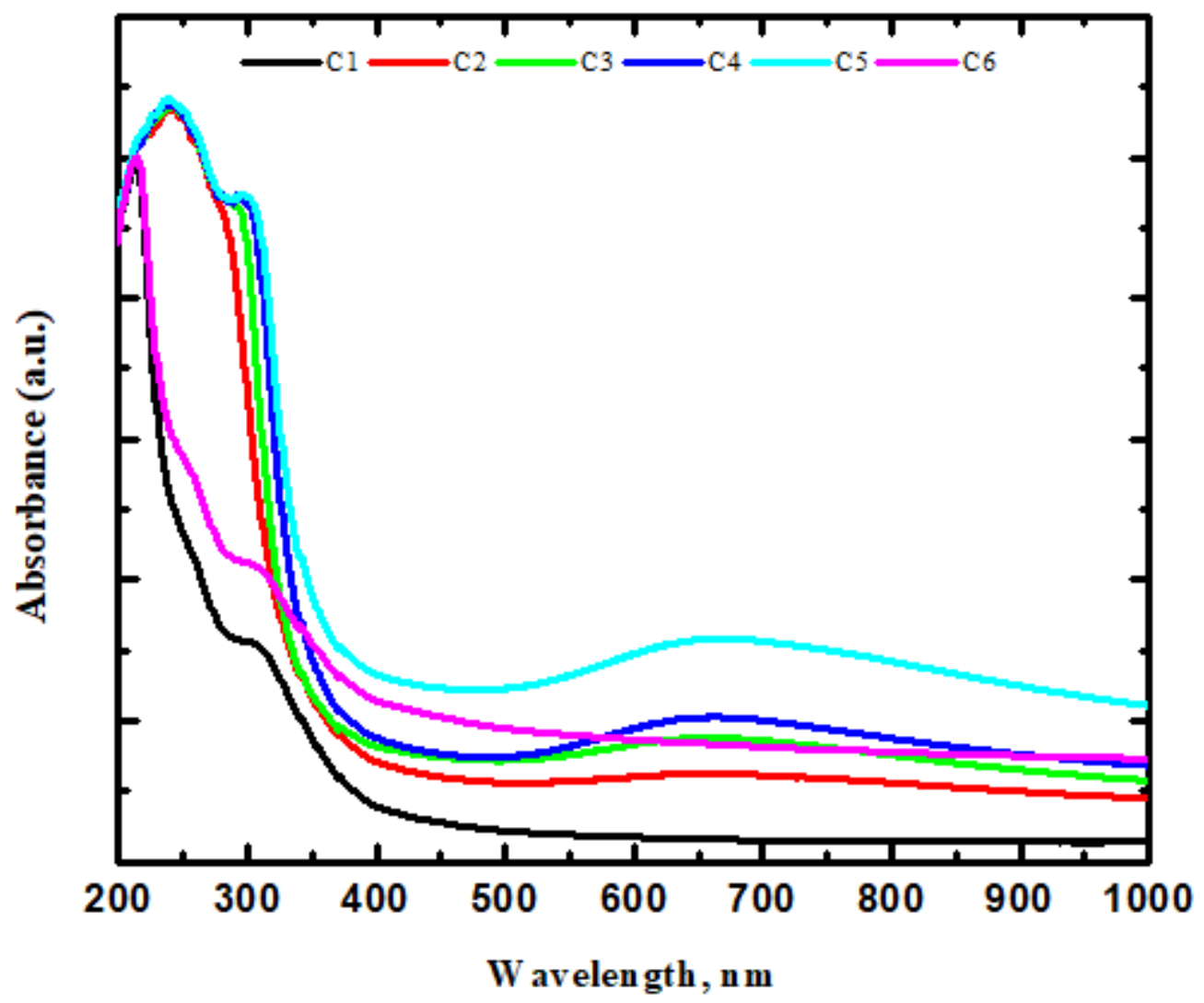

Figure 1

UV-Vis absorption spectra of pure Cs, Cs substituted with 2, 4, 6 and $8 \mathrm{wt} \%$ of CuO, and Cs with $2 \mathrm{wt} \%$ of GO 


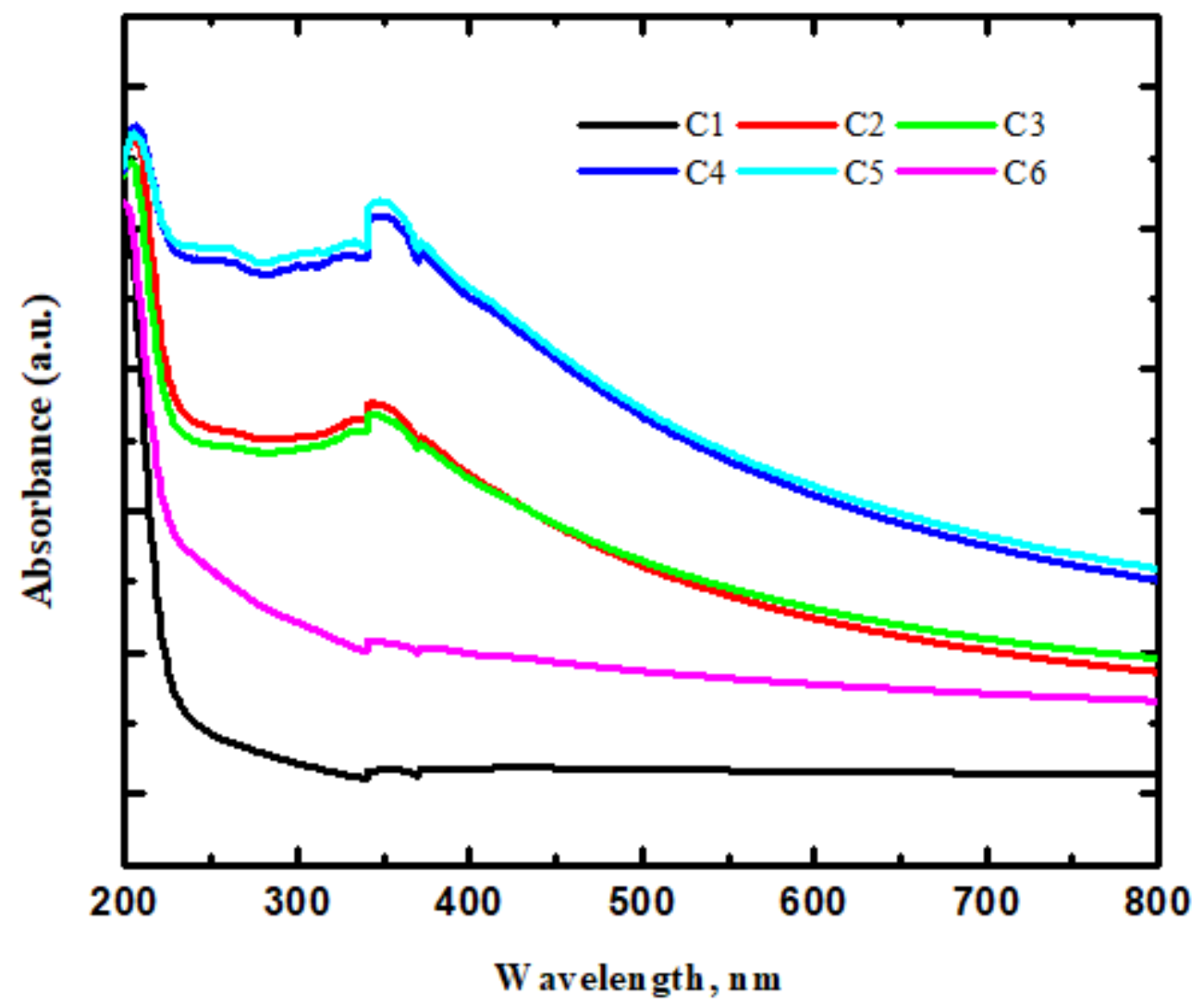

Figure 2

UV-Vis. absorption spectra of pristine $\mathrm{CMC}, \mathrm{CMC}$ with $2,4,6$ and 8 wt\% of $\mathrm{TiO}_{2}$, and $\mathrm{CMC}$ with $2 \mathrm{wt} \% \mathrm{GO}$ 


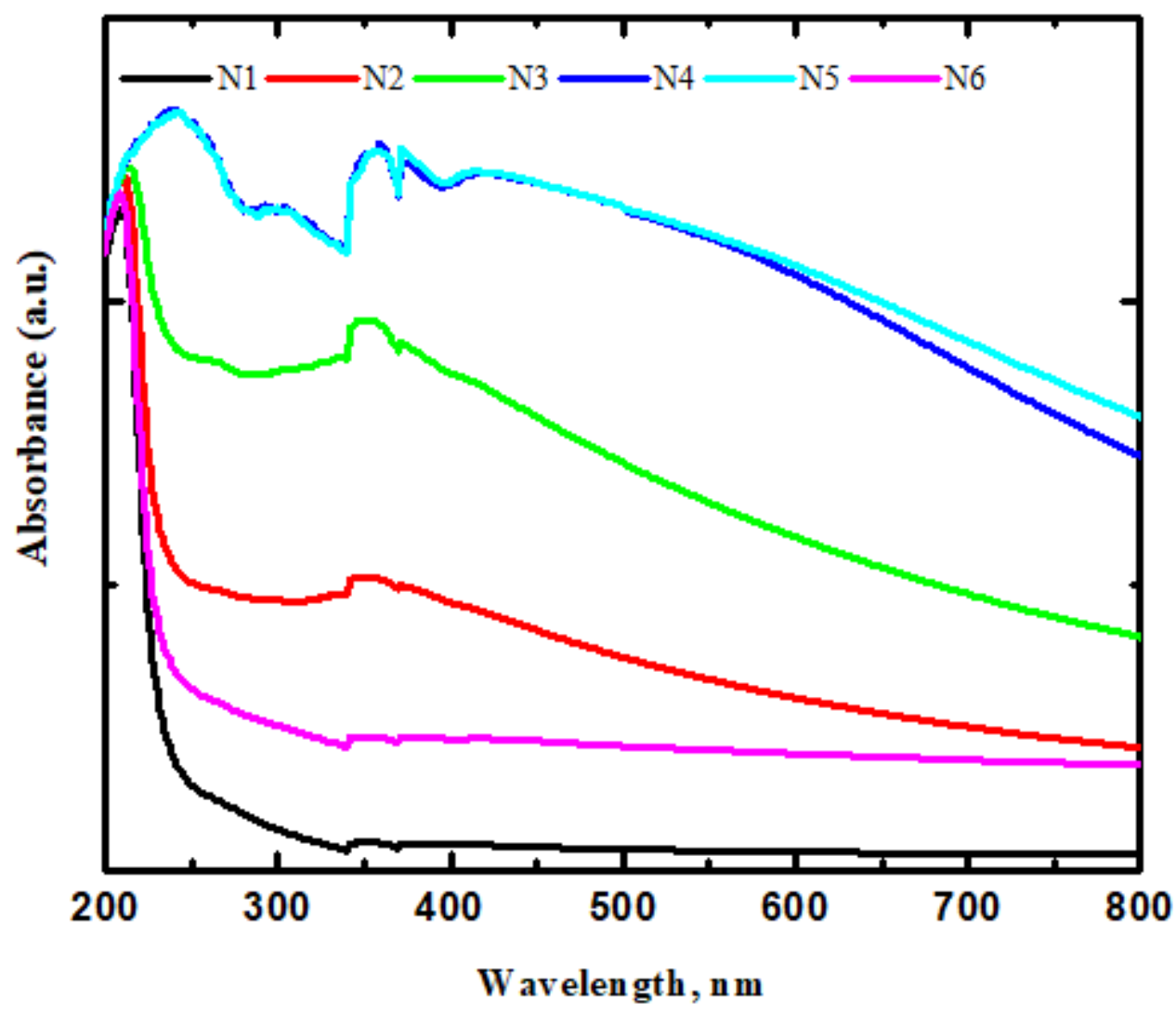

Figure 3

UV-Vis absorption spectra of pristine Na-Alg, Na-Alg with 2, 4, 6 and 8 wt\% of $\mathrm{TiO}_{2}$, and $\mathrm{Na}-\mathrm{Alg}$ with 2 wt\% GO 


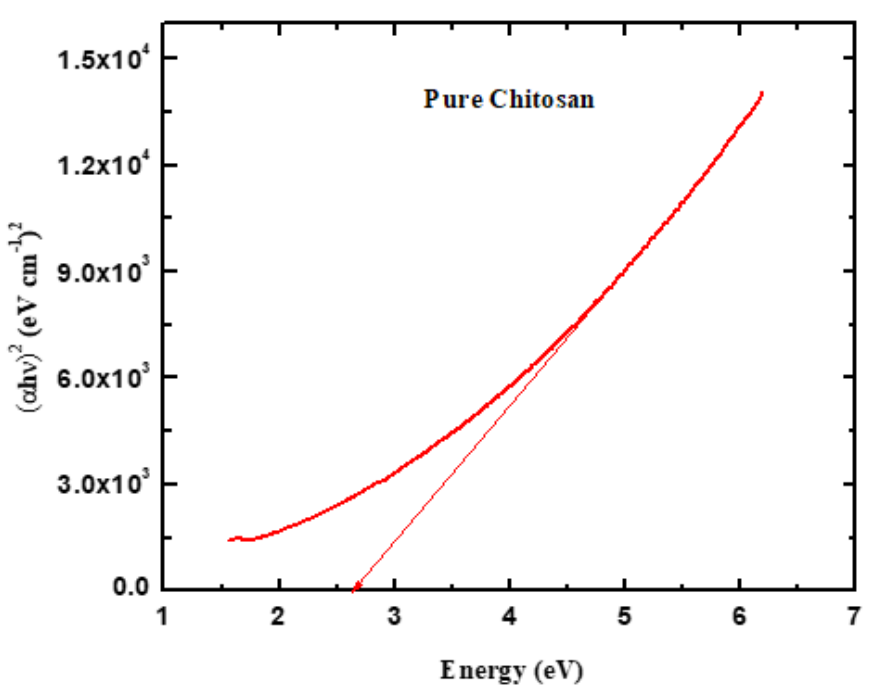

(a)

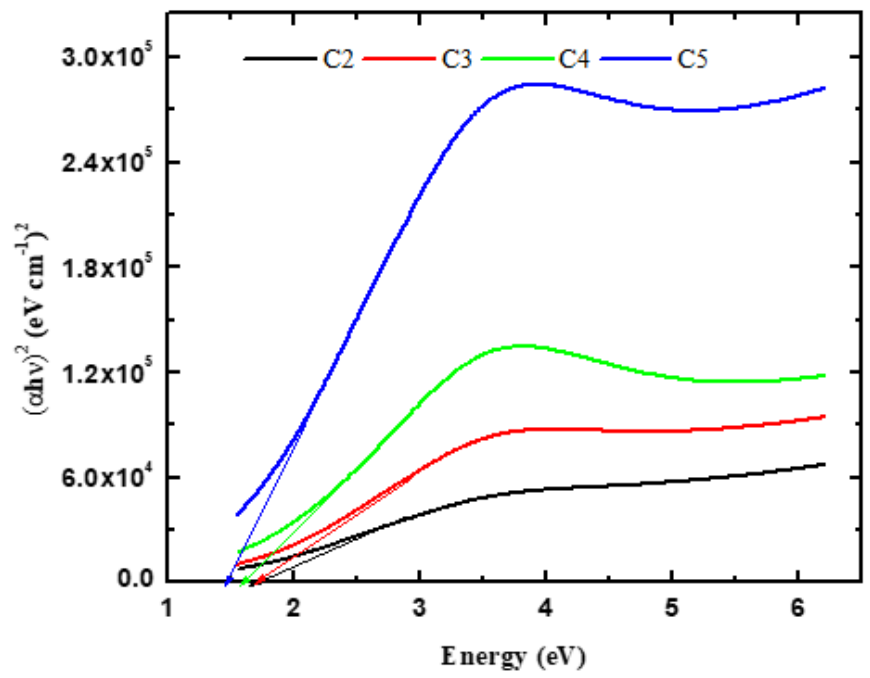

(b)

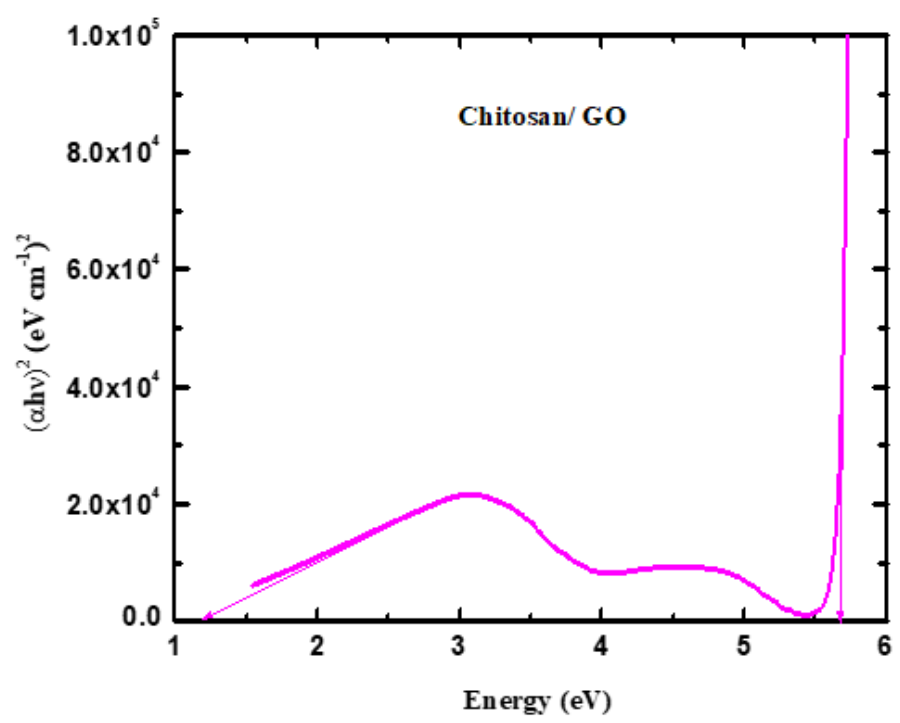

(c)

\section{Figure 4}

Relation between (ahu) ${ }^{2}$ and photon energy (hu) for a pure Cs; $\mathbf{b} \mathrm{Cs} / \mathrm{CuO}$ nanocomposite with different concentrations of $\mathrm{CuO}(2,4,6$ and $8 \mathrm{wt} \%)$; and $\mathrm{c} \mathrm{Cs} / \mathrm{GO}$ nanocomposite 


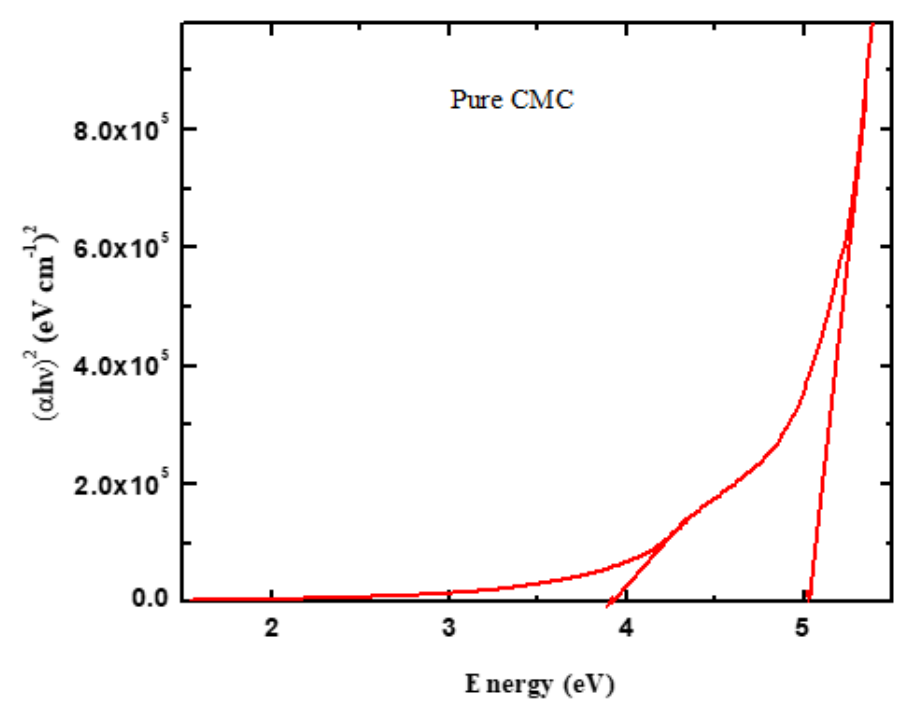

(a)

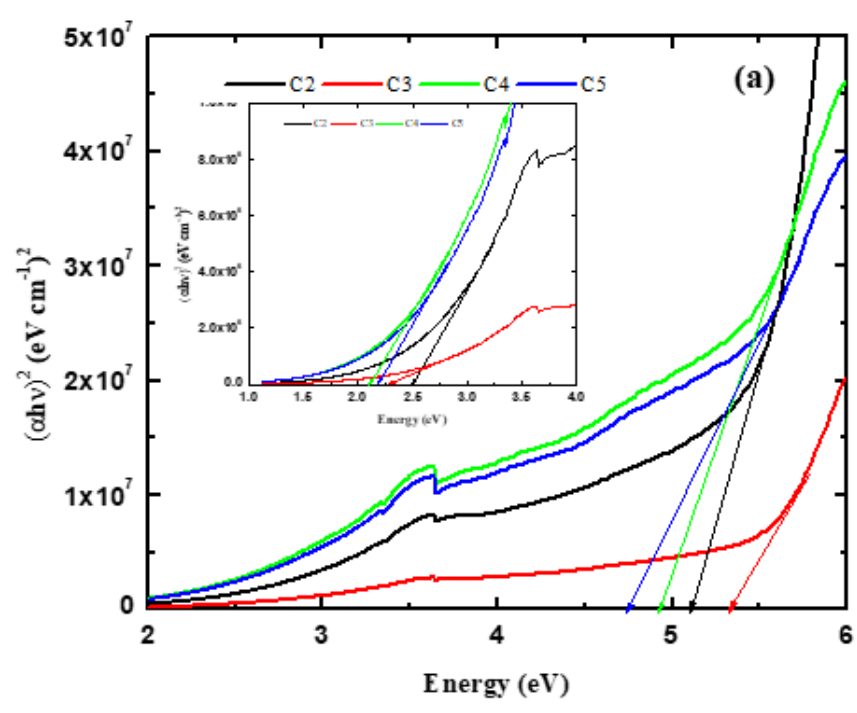

(b)

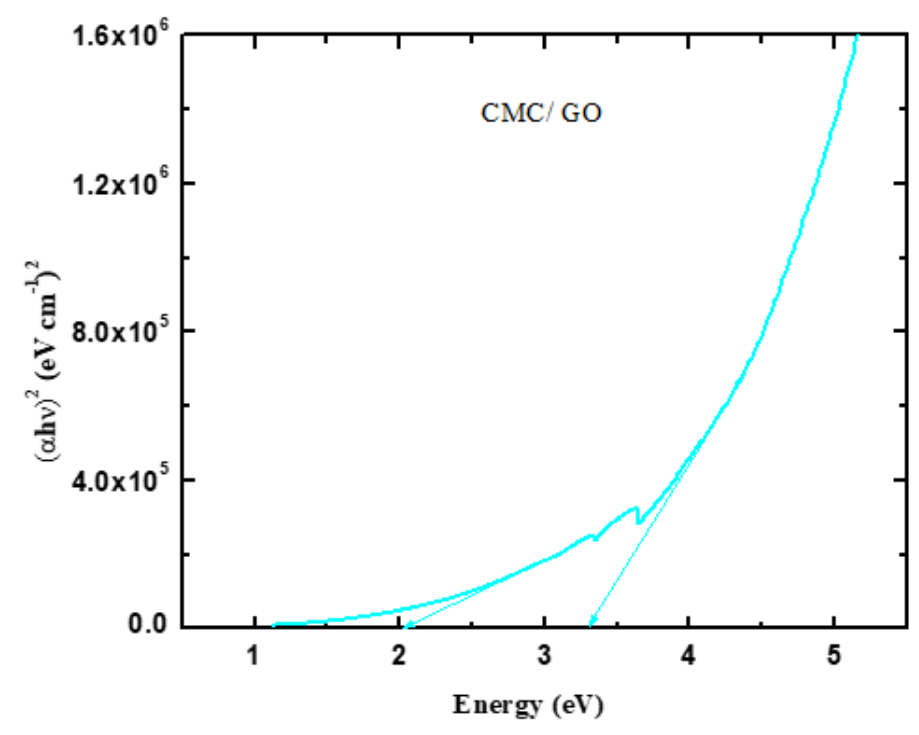

(c)

\section{Figure 5}

Relation between (ahu) ${ }^{2}$ and photon energy (hu) for a pure CMC; $\mathbf{b} \mathrm{CMC} / \mathrm{CuO}$ nanocomposite with different concentrations of $\mathrm{CuO}(2,4,6$ and 8 wt\%) and $\mathrm{c}$ CMC/GO nanocomposite 


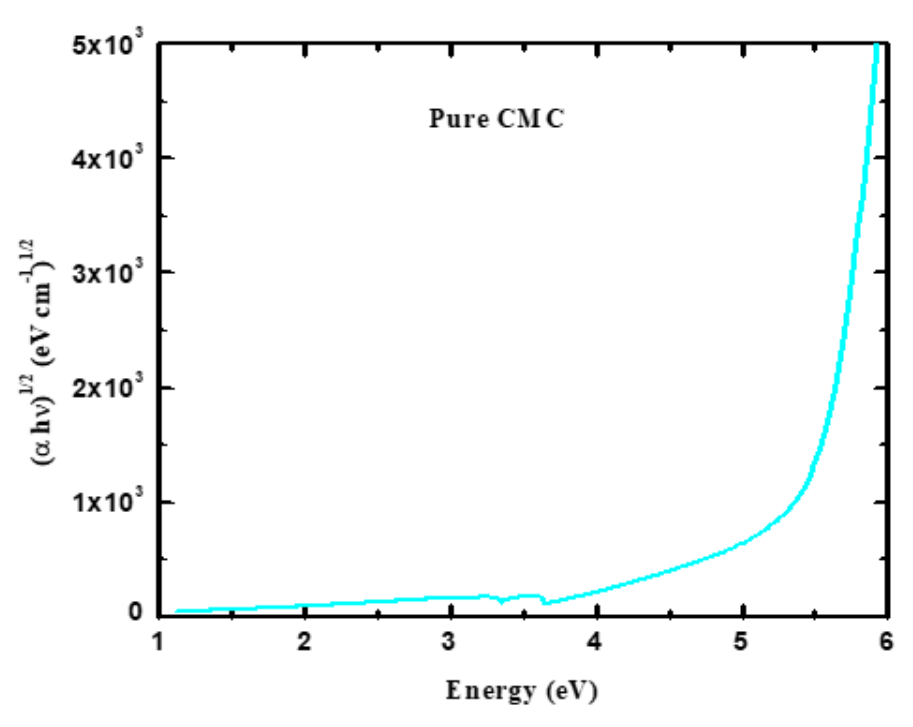

(a)

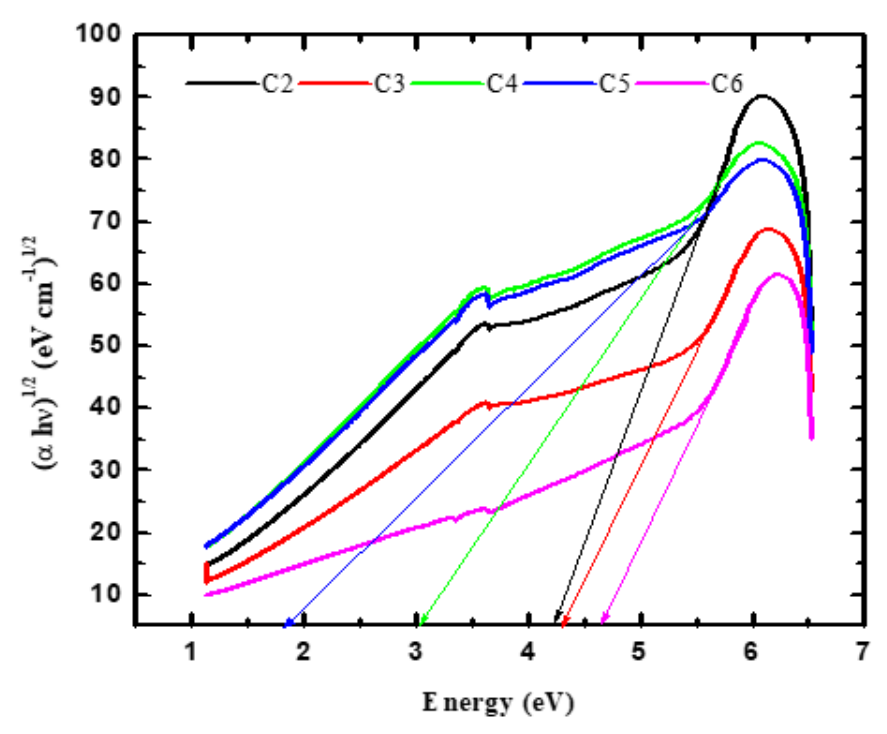

(b)

Figure 6

Relation between (ahu) $)^{1 / 2}$ and photon energy (hu) for a pure $\mathrm{CMC}$; b CMC/CuO with different concentrations of $\mathrm{CuO}(2,4,6$ and $8 \mathrm{wt} \%)$ and $2 \mathrm{wt} \% \mathrm{GO}$

Figure 7

Relation between (ahu) ${ }^{2}$ and photon energy (hu) for a pure Na-Alg; b Na-Alg/2 wt\% CuO; c Na-Alg /4 wt\% CuO; d Na-Alg/6 wt\% CuO e; Na-Alg/8 wt\% CuO; f Na-Alg/2 wt\% GO 